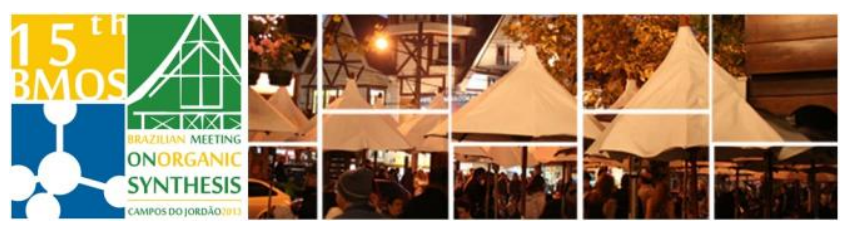

\title{
Synthesis of novel 6-seleno-dihydropyrimidinones: Potentially bioactive compounds
}

\author{
Flavio A. R. Barbosa ${ }^{1,{ }^{*}}(I C)$, Rômulo F. S. Canto ${ }^{1}(P G)$, Antonio L. Braga ${ }^{1}(P Q)$ \\ ${ }^{1}$ LabSelen - Laboratório de Síntese de Substâncias Bioativas de Selênio, UFSC, Florianópolis - SC \\ *e-mail corresponding author: flavioauggusto@gmail.com
}

Keywords:organochalcogenides, selenocyanates, Biginelli compounds

\section{INTRODUCTION}

Organoselenium compounds $^{1}$

and dihydropyrimidinones $^{2}$ (DHPMs) are biologically privileged classes of compounds due to its interactions with a wide range of molecular targets what leads to distinct pharmacological activities. Recent studies have shown that DHPMs are capable to act as anti-inflammatory and antitumoral agents ${ }^{2}$.The same activities are described for organoselenium compounds ${ }^{1}$, however, the mechanism of action of both classes are not supposed to be the same. Exploring the versatility of the Biginelli scaffold and the biological activities presented by organochalcogens, a series of novel potentially bioactive 6-seleno-dihydropyrimidinones was synthesized in this work. This new hybrid compounds are potential drug candidates, and we can also expect a possible synergism between the different pharmacophores.

\section{RESULTS AND DISCUSSION}

The starting materials 6-Cl-DHPMs(1)were synthesized trough the classical Biginelli multicomponent reaction using 4-Clethylacetoacetate (2) as the dicarbonyl component (Scheme 1).

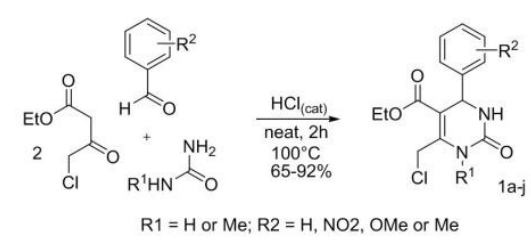

Scheme 1 - General synthesis of DHPMs.

After preparation of $\mathbf{1 a - j}$ intermediates, several DHPMs functionalized with selenides at the position 6 were synthesized (2a-h, Scheme 2). The compound derived from reductive dehalogenation of the $\mathrm{C}-\mathrm{Cl}$ bond was detected as a byproduct of these reactions ${ }^{3}$, and that is why the reaction could not be extended to telurides. The intermediates 1a-j was also used in the synthesis of the respective diselenides (3a-d) in moderate yelds. The dihydropyrimidinones 1a-j were also substrates for the nucleofilic substitution with potassium selenocyanate at the position 6 , giving rise to selenocyanates derived from pyrimidinones (4a-j Scheme 3). Selenocyanides has been shown to be potential antitumor agents ${ }^{1}$. Selenoesters derived from pyrimidinones were also synthesized (5a-d Scheme 3). The selenoesters were prepared from intermediates 1a-j and selenocarboxylates generated in situ from $\mathrm{NaSeH}$ and $p$-toluil chloride ${ }^{4}$.

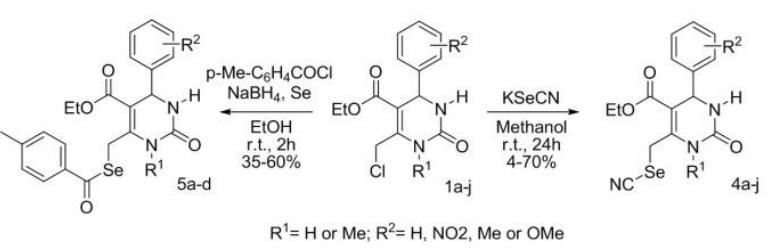

Scheme 2 -Synthesis of selenides and diselenides

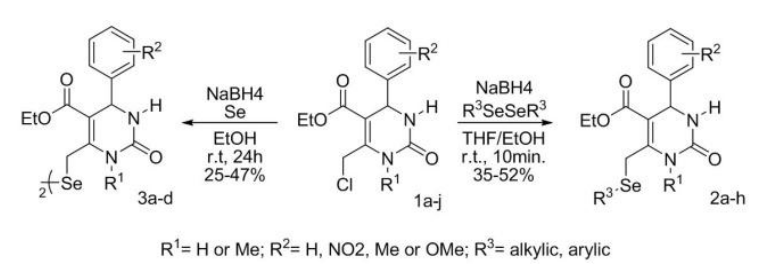

Scheme 3-Synthesis of selenoesters and selenocyanates

\section{CONCLUSION}

In this work a novel class of 6-seleno-pyrimidinones was synthesized with various selenium-containing functional groups.Compounds with variation on the heterocyclic moiety as well as bearing selenides, diselenides, selenocyanates and selenoesters as functional groups were synthesized. Investigations on the pharmacological activities of these compounds are being made in our laboratory.

\section{ACKNOWLEDGEMENTS}

UFSC, CNPQ, CAPES, INCT-Catálise and Cebime for mass spectroscopy analysis.

\section{REFERENCES}

${ }^{1}$ Nogueira, C. W.;Zeni, G.; Rocha, J. T. B.Chem. Rev.2004, 104, 6255.

${ }^{2}$ Sandhu, S.; Sandhu, J.S.Arkivoc2012, I, 66.

${ }^{3}$ (a) Li, C.J.; Harpp, D.N. Tetrahedron Lett. 1991, 32, 1545. (b)

Engman, L.; Cava, M.P. J. Org. Chem. 1982, 47, 3946.

${ }^{4}$ Athayde-Filho, P. F.; Souza, A. G.; Morais, S.A.; Botelho, J. R.;

Barbosa-Filho, J. M.; Miller, J.; Lira, B. F. Arkivoc2004, vi, 22. 